\title{
VIBRATIONAL TESTS AND ANALYSIS ON MATERIALS USED IN AIRCRAFT
}

\author{
Sándor Csikós, Tamás Molnár, Péter Szuchy, László Gogolák, István Bíró, József Sárosi \\ Department of Technology, Faculty of Engineering, University of Szeged, Mars tér 7. 6724, Szeged, Hungary \\ e-mail: csikos-s@mk.u-szeged.hu
}

\begin{abstract}
The current cargo capacity for aircraft is about $20 \%$ of their total weight, increasing this ratio would significantly increase the economics of aircraft logistics. This is why it's important for material sciences to advance so that the materials used in aircraft construction become lighter while still retaining their structural integrity. In this paper we examined materials used in aircraft construction (steel, aluminum, plastics and composites) at the University of Szeged Faculty of Engineering. Using vibrational analysis we analyzed the test pieces for their natural frequency, we did this to gain insight to the range of frequencies that are least attenuated by the material the aircraft wings are made from. Using the data we gathered we wish to draw conclusions to which materials are more suited for aircraft wing construction.
\end{abstract}

Keywords: composites, vibrational analysis, material science

\section{INTRODUCTION}

In this paper we set out on the path to discover the resonant frequencies of materials used in aircraft construction. The motivation was to increase the ratio of cargo weight compared to the aircraft's weight. This would mean a more energy efficient aircraft which in turn could lower future prices for shipping or air travel in general. Vibrational analysis is an important tool in many fields of engineering. It can supply us with information on frequency ranges we should avoid given a certain construct. Also since materials in construction age they are subject to wear which can be detected by vibrational analysis. Vibrational analysis has been used for similar purposes in material science, recently in the field of meta materials, where the structure of the material is modified to suit a specific requirement [1-5]. With the right combination of materials and lattice structure these meta materials can achieve vibration attenuation over a specified range, the range we can define by finding the resonant frequencies of the materials chosen. Materials currently used in aircraft construction are aluminium alloys, steel, titanium alloys, composites.

Aluminium is employed due to its low density $\left(2.7 \mathrm{~g} / \mathrm{cm}^{3}\right)$, hi-strength properties, good thermal and electric conductivity, technological effectiveness and high corrosion resistance. But because aluminium loses its strength in great heat, it is not used on the surface of an aircraft.

Steel is a blend of iron and carbon and can be 3 times stronger and denser than aluminium. It is usually used in the landing gear due to their strength and hardness as well as in the surface of aircrafts due to its high heat resistance.

Titanium and its alloys are generally used in the construction of aircraft due to its overall strength, temperature resistance and high deterioration resistance compared to stainless steel and aluminium. Despite being expensive, titanium is utilized in aircraft construction due to its excellent material properties. It is employed in panel and swivel wing devices, hydraulic systems and other parts.

Composite materials are utilized in the production of aircrafts due to their high tensile strength, resistance to compression, low weight and overall resistance to deterioration. Composite materials are composed by way of a base material and bonding agent that strengthens the material all together. Composite materials 
improve fuel economy and performance of the aircraft as well as reduce direct operating costs of aircrafts. The most abundantly used composite material is fibre glass that comprises of glass fibres as the base substance and a resin mesh. The downside of using amalgamated materials, however, include high cost and the fact that immediate repair is needed in case of harm. Avoiding fire is also very important when you use composite materials because the resin used weakens and causes the release of poisonous fumes.

\section{MATERIALS AND METHODS}

The first step to achieving our goal was to acquire the materials that are commonly used in aircraft construction, to set a baseline we also acquired some materials that are not used in aircraft construction but are readily available and their properties widely documented. We made contacts with the trading companies in Csongrád county where we could procure the structure materials S235, S275, S355 in different thickness. For purchasing technical plastics the Kár-Plaszt $2000 \mathrm{Kft}$. based in Szeged helped us with plastics produced by them, so we could manufacture the standard test specimens. The aluminium alloys applied in aircraft industry were cut out at the airport of Szeged from the wing structure of a used fixed-wing aircraft (therefore we had got authentic values for the mechanical features), from which the tensile specimens were made (Fig. 1).

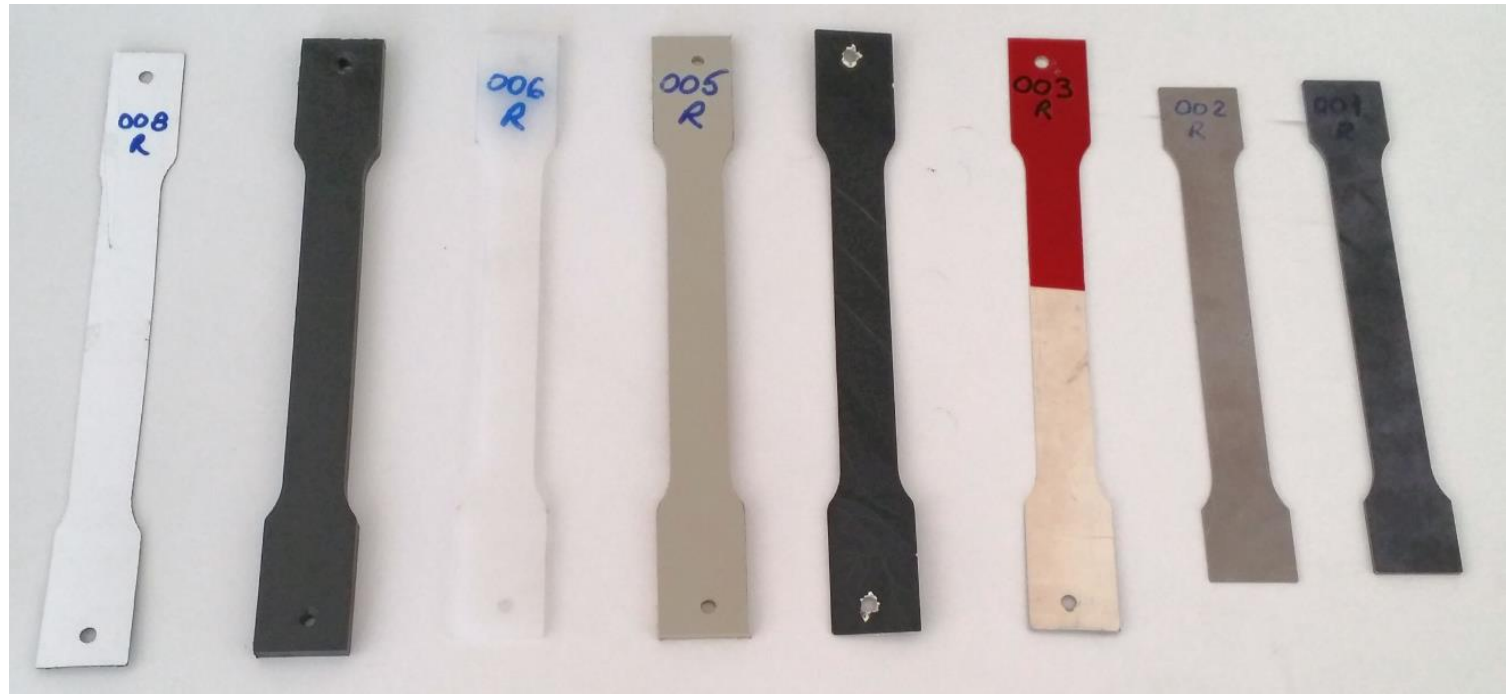

Figure 1. Materials selected to measure resonant frequencies.

Following the acquisition of materials we acquired the software to set frequencies applied to the materials and visualize and evaluate the results. For this purpose we used the RT photon+ software (Fig. 2) device that we will use to generate specific frequencies using the Brüel \& Kjaer 892070 LDS VIBRATOR, V201 (Shaker). To drive the shaker we needed a suitable amplifier for this purpose we used the Brüel \& Kjaer 4070050-X03 LDS LPA100 - 230V. 


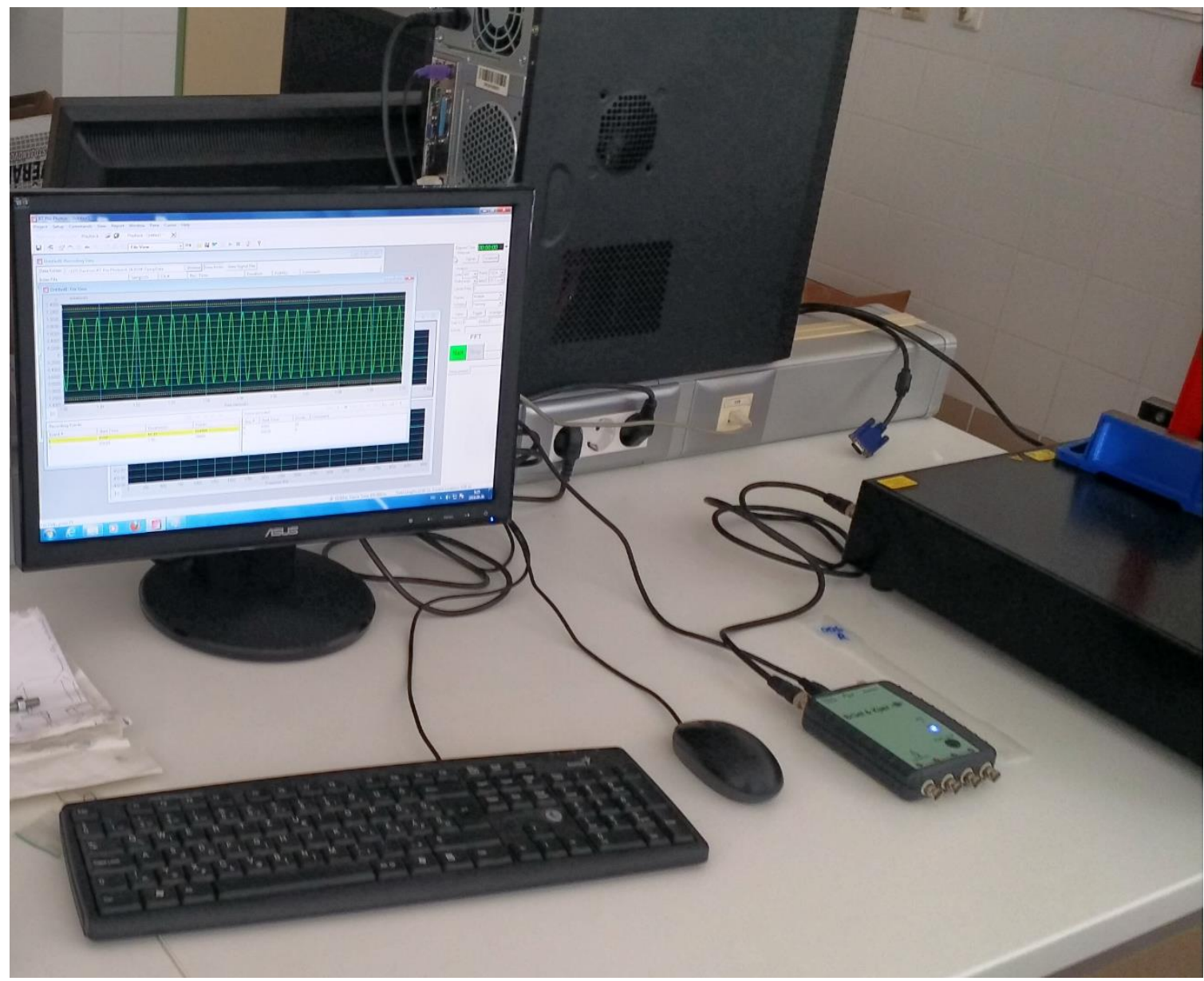

Figure 2. RT photon+ software and DAQ.

Next we designed a test bench on which we will be able to measure the test pieces. The bench consists of a heavy metal frame, a vertically adjustable vice to hold the test pieces and the shaker unit (LDS V201) (Fig $3)$. The vibration will be measured with accelerometers, one will always be on the shaker giving us feedback of the actual system input and one will be placed on the test piece where we can measure the response of the material to the excitation frequency.

The process of the measurement will take the following steps, we will set the shaker to output white noise with no test piece attached, only the accelerometer. By applying a Fourier transform to this measured signal we will get the bode diagram of the shaker where we can see which frequencies will be attenuated. Since white noise has a uniform frequency spectrum we want to see uniform attenuation on all frequencies, but since this is a physical system such an ideal response is highly unlikely. Some frequencies are bound to be attenuated, according to the handbook of the LDS V201, depending on the mass that the shaker has to excite the frequency range that we can use starts from $80 \mathrm{~Hz}$. Below this the gain is non uniform, to circumvent this and enable the output of a more uniform white noise we will fit a function that will correct the attenuation of the frequencies close to uniform. Following this process we can attach a test piece and 
apply the now corrected white noise. As before the accelerometer placed on top of the test piece will provide a response to the excitation signal, where looking for sharp peaks we can see the resonance frequencies.

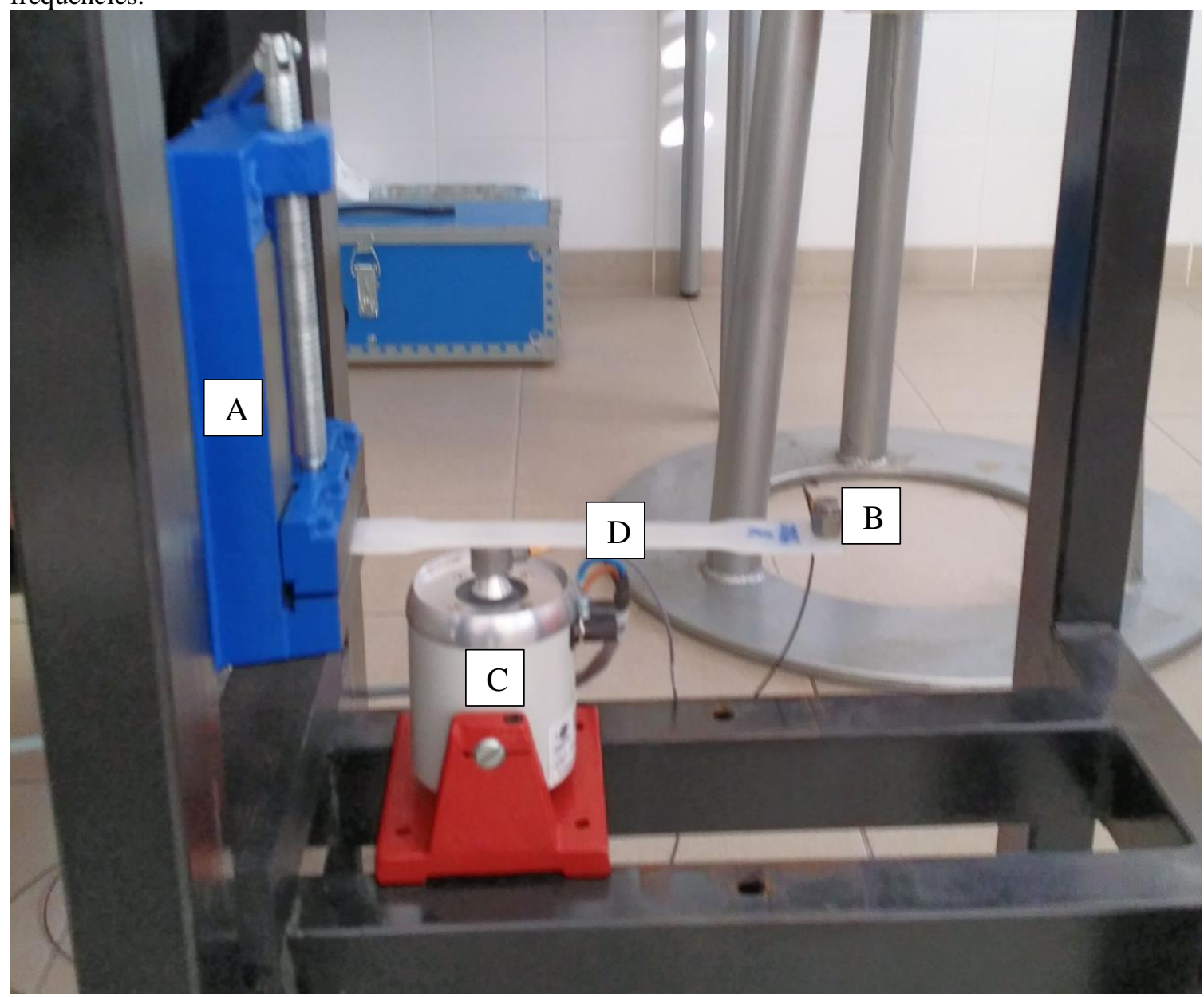

Figure 3. Test bench (A-vice, B-Accelerometer, C-Shaker, D-test piece).

\section{RESULTS, DISCUSSION}

Once the resonant frequencies are found for each material, the work pieces will be excited at that frequency for a set amount of time. This should create wear in the materials structure. Following this excitation we will perform tensile tests on each of the test pieces. Drawing a baseline with test pieces that were not excited and thus have no wear we can compare the tensile strength of those pieces which were excited for a set period of time. By varying the time these test pieces were excited we can gather more data points, and draw conclusions to which material would be best suited for set objectives. 


\section{FUTURE WORK}

In future works we hope to draw conclusions to the question which material is most suited for aircraft construction if we want to enhance energy efficiency. Following that we can find out how that materials tensile strength reacts to varying temperatures, also if by using different lattice structures we would get better results than with a solid structure.

\section{ACKNOWLEDGEMENTS}

The project has been supported by the European Union, co-financed by the European Social Fund. EFOP3.6.1-16-2016-00014. Authors are thankful for it.

\section{REFERENCES}

[1] E.D. Nobrega, et al., Vibration band gaps for elastic metamaterial rods using wave finite element method, Mech. Syst. Signal Process. (2016)

[2] Zhu, R., et al. "A chiral elastic metamaterial beam for broadband vibration suppression." Journal of Sound and Vibration 333.10 (2014): 2759-2773.

[3] Y. Xiao, J.H. Wen, X.S. Wen, Longitudinal wave band gaps in metamaterial-based elastic rods containing multi-degree-of-freedom resonators, New Journal of Physics 14 (2012) 033042.

[4] Z.Y. Liu, X.X. Zhang, Y.W. Mao, Y.Y. Zhu, Z.Y. Yang, C.T. Chan, P. Sheng, Locally resonant sonic materials, Science 289 (2000) 1734-1736.

[5] D. Mead, Wave propagation and natural modes in periodic systems: I. Mono-coupled systems, J. Sound Vib. 40 (1) (1975) 1-18 